\title{
Building a Bridge to the Future: Some Points to Ponder
}

Since 1947 respiratory therapists (RTs) have provided clinical services to tens of millions of patients with pulmonary diseases in North America. In the United States, we, as RTs, evolved as a profession because of external factors, such as the healthcare environment and clinical needs of our patients, as well as the internal factors that built our current education system, program accreditation, and competency documentation/credentialing systems. The latter includes both legal credentialing (licensure) and voluntary credentialing (eg, certified respiratory therapist [CRT] and registered [RRT] respiratory therapist). External factors are generally the first to trigger change in healthcare systems. It is easier to identify unmet patient and health-system needs than it is to reach agreement on precisely how we are to meet those needs.

Reacting to challenges is good, but anticipating challenges is even better. That is why the Board of Directors of the American Association for Respiratory Care (AARC) authorized a project to begin the process of thoughtful planning for the future of respiratory care, and to anticipate the future roles of those persons providing respiratory care services. Once that first step was taken, we then needed to identify the competencies, knowledge, skills, and attributes that future providers must own in order to execute their future roles successfully and meet the needs of our patients.

Of course, if we stopped at that point, our task would be incomplete. It is not enough to anticipate our future role, competencies, and skills. If our profession is unable to transition from where we are today to where we will need to be tomorrow, we will fail. It reminds me of a slogan I have seen over the years, that goes something like "The road ahead is never a dead end, unless you fail to make the turn." To take this analogy a bit further, it does not matter if we know how to drive the car, nor that we built the right car, unless we are able to add that third ingredient, "making the turn." Thoughtful transition is required so RTs will be at the top of their game when caring for patients in the future.

The AARC's "2015 and Beyond" project was launched in 2007, to set future directions for the respiratory care profession in the United States. In my capacity as Executive Director of the AARC, I was asked to organize a series of 3 conferences to answer the previously posed questions regarding our future. Thus, we invited representatives from all stakeholder groups, including not only
RTs, but also physicians, payers, government officials, credentialers, accreditors, patients, and employers. As you might imagine, there was a high degree of interest in the conferences. And, certainly, as you will read, at every conference there was no shortage of diversity of opinion. This was encouraging.

I would like to offer a few points for you to consider as you read, in this issue of the Journal, the paper that describes the third and final conference, in July $2010 .{ }^{1}$ My first suggestion is to review the papers that describe the first 2 conferences. ${ }^{2,3}$ The first was "Creating a Vision for Respiratory Care in 2015 and Beyond."2 Do you want to see our future? Read that paper. Since it was published in 2009 we have not received one letter stating disagreement with that vision. The second conference focused on identifying the competencies, knowledge, skills, and attributes required to fulfill those future roles, and the proceedings were published in the 2010 paper, "Competencies Needed by Graduate Respiratory Therapists in 2015 and Beyond."3 There was fairly broad consensus with regard to the needed competencies, knowledge, skills, and attributes, but when it came to attempting to parse the entry level and advanced level, there was less consensus. Do you want to know about the future competencies you'll need? Read that paper.

See the Special Article on Page 681

The third and final conference focused on transition issues. It attempted to answer the question, how do we take the profession from where we are today to where we need to be in the future, and to optimize our role and value for our patients and our employers? As you will see, the paper contains recommendations that were developed from opinions expressed during the conference. The recommendations run the gamut from mandating a minimum baccalaureate degree to exploring the use and creation of an RT assistant. Please bear in mind as you read the paper ${ }^{1}$ that the recommendations did not originate from the AARC or the other organizations mentioned in many of the recommendations, but, rather, from those attending the conference. And please note that conferees were invited to represent the diverse perspectives of different members of our community, rather than the position of any one organization. 
There were also opinions and recommendations from conferees related to our current examination system. Those of you who have been around the profession for a long time will see few surprises here. What you will see is what has been discussed over the last 20 years in other meetings of our colleagues. Some conferees had biases and convictions, but they also had the courage to express those convictions. There is nothing wrong with such an exchange of ideas and remedies. We wanted diverse opinions because we wanted consideration of all ideas for a transition plan.

The AARC leadership, working with the respiratory care community, will continue to plan for the future of our profession in a way that is consistent with the values of our American health system and the needs of our patients. While the recommendations, at least in some cases, may not seem practical (and some might argue that they may impinge upon our ability to generate enough RTs in the future), it was important to list every possible option and to investigate not just the desirability but the practicality of the recommendations. We can learn from the evolution of other professions and avoid unintended consequences that could prove negative for our patients, such as an inadequate number of RTs.

The "2015 and Beyond" planning committee developed a list of attributes that any transition plan must possess if it is to be supported by the AARC Board of Directors. I won't recite them all here, but as you will see from Table 1 in the paper, ${ }^{1}$ most of the recommendations are straightforward common sense. I do want to point out that the AARC Board of Directors eliminated one attribute from this table: that related to not reporting recommendations that did not receive a plurality of votes from conferees. This point was eliminated to ensure that the AARC Board of Directors considered all recommendations, and, more importantly, maintained process transparency.

The attributes discussed in the paper will be key to our success. The AARC will not create a future system that fails to produce adequate numbers of RTs in the United States. It will not undertake any changes unless the case has been established that our future roles, skill sets, and education are consistent with the values of our patients, our employers, and our healthcare system.

The AARC is far from finished with this project. Indeed, it has just begun. The 3-conference series was the first phase to frame the issues, regardless of whether they

The author has disclosed no conflicts of interest.

Correspondence: Sam P Giordano MBA RRT FAARC, American Association for Respiratory Care, 9425 MacArthur Boulevard, Suite 100, Irving TX 75063-4706. E-mail: giordano@aarc.org.

DOI: $10.4187 /$ respcare. 01331 are pro-change, anti-change, for more education, for less education, for more testing, or for less testing. It reminds me of that commercial for a spaghetti sauce: "It's in there!" Indeed, everything is on the table. That is as it should be, since we are considering the future direction of our profession. No idea was, or is, out of bounds. If, as you read this paper, ${ }^{1}$ you come up with an idea that we should consider, please send it in to the AARC President.

As we move our profession forward, we face some difficult questions. Particularly thorny is the question of whether our current education system is able to prepare graduates with the expanded skills inventory identified in the second conference. Understandably, some of our colleagues feel threatened. Others, who want to increase education, are dealing with the challenge of the current system to produce adequate numbers of RTs at that higher education level.

These are just some of the reasons the AARC Board of Directors is investigating each and every recommendation in this paper. ${ }^{1}$ The board's first action is to conduct a crosswalk between all of the recommendations from the third conference and the transition plan attributes. Remember, these must be followed to assure that we avoid negative consequences for the patients and our profession. Thus far, the board has approved only the transition plan attributes, after eliminating the previously mentioned point from Table 1 to maintain transparency.

The Board of Directors is performing due diligence to responsibly consider all recommendations. This includes gathering input from stakeholder organizations and our community before addressing the recommendations themselves. This process is proving long and arduous. However, given the importance of this project, how can we do less than our very best? We are facing tremendous challenges and opportunities in the future. And now that we have the beginnings of a plan to prepare for that future, the continued evolution of the profession of respiratory therapy is guaranteed.

Sam P Giordano MBA RRT FAARC American Association for Respiratory Care Irving, Texas

\section{REFERENCES}

1. Barnes TA, Kacmarek RM, Kageler WV, Morris MJ, Durbin CG. Transitioning the respiratory therapy workforce for 2015 and beyond. Respir Care 2011;56(5):681-690.

2. Kacmarek RM, Durbin CG, Barnes TA, Kageler WV, Walton JR, O'Neil EH. Creating a vision for respiratory care in 2015 and beyond. Respir Care 2009;54(3):375-389.

3. Barnes TA, Gale DD, Kacmarek RM, Kageler WV. Competencies needed by graduate respiratory therapists in 2015 and beyond. Respir Care 2010;55(\%):601-16. Erratum in: Respir Care 2010;55(6):789. 